\title{
Commentary: Failing grades
}

\author{
Jacob A. Klapper, MD
}

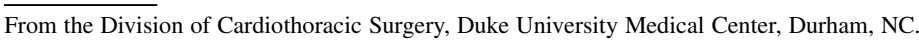

Disclosures: Author has nothing to disclose with regard to commercial support.

Received for publication March 2, 2019; accepted for publication March 4, 2019; available ahead of print April $28,2019$.

Address for reprints: Jacob A. Klapper, MD, Division of Cardiothoracic Surgery, DUMC 3954, Durham, NC 27710 (E-mail: Jacob.klapper@duke.edu).

J Thorac Cardiovasc Surg 2019;158:965

$0022-5223 / \$ 36.00$

Copyright (C) 2019 Published by Elsevier Inc. on behalf of The American Association for Thoracic Surgery https://doi.org/10.1016/j.jtcvs.2019.03.037

The Innocence Project is a network of lawyers and volunteers who during the last 25 years have dedicated themselves to the exoneration of the wrongfully accused and convicted. Through diligent work, these individuals have shown how prosecutorial misdeeds, unreliable witnesses, and even pseudoscience have led many people to spend decades of their lives in prison. One such client, Timothy Bridges, spent 25 years in jail for a crime that he did not commit after an original conviction that was based largely on the imperfect science of hair analysis. Now free because of DNA evidence, Mr Bridges is a prime example of how our reliance on flawed instruments for measuring and deciding outcomes can have dire consequences.

The article in this issue of the Journal by Schwarz and colleagues ${ }^{1}$ presents a compelling analysis of how our current criteria for measuring primary graft dysfunction is just as flawed as, say, hair analysis. Not only do Schwarz and colleagues $^{1}$ demonstrate how infrequently experienced chest radiologists agree on film interpretation when they do not know relevant clinical data, they also show how consensus does not improve when they do have more insight. In addition, they further show how in cases of patients with low $\mathrm{PaO}_{2}$ /inspired oxygen fraction ratios $(<200 \mathrm{~mm} \mathrm{Hg})$, the variability in chest film interpretation can yield significant fluctuations in primary graft dysfunction scoring. In the end, although the inadequacy of this scoring system may not rise to the level of deciding a given person's fate, the current method for measuring primary graft dysfunction forms the foundation for a large body of literature that assesses risk factors for graft dysfunction and its long-term implications (ie, survival). ${ }^{2}$ Furthermore, its use as a primary study end point has led to the recent US

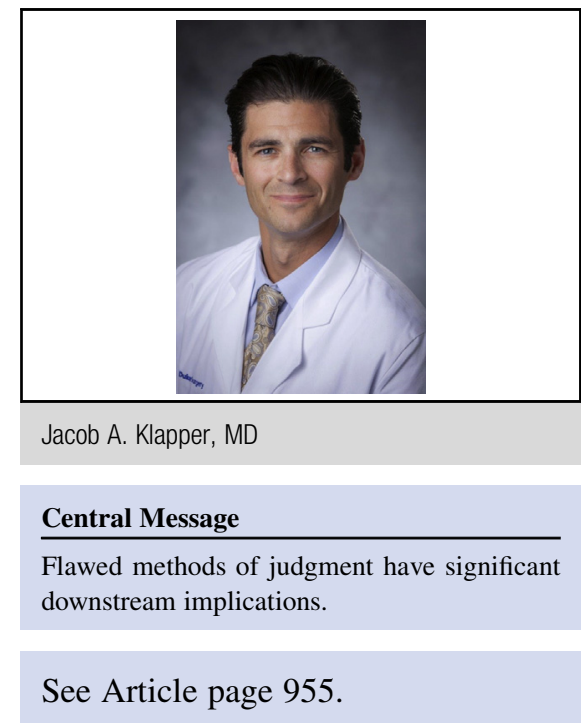

Food and Drug Administration approval of an expensive portable ex vivo lung perfusion device. ${ }^{3}$

In any field of science, whether it be forensic or medical science, there is as much value in work that questions perceived wisdom as there is in the discovery of new knowledge. This is particularly true when conclusions are being drawn and crimes adjudicated according to methodology that is dependent on a human being's subjective analysis. When light is shined upon these errors in judgment, as Schwarz and colleagues ${ }^{1}$ do here, we bend a bit closer to the ultimate goal-truth.

\section{References}

1. Schwarz S, Muckenhuber M, Benazzo A, Beer L, Gittler F, Prosch H, et al. Interobserver variability impairs radiologic grading of primary graft dysfunction after lung transplantation. J Thorac Cardiovasc Surg. 2019;158:955-62.e1.

2. Diamond JM, Lee JC, Kawut SM, Shah RJ, Localio AR, Bellamy SL, et al; Lung Transplant Outcomes Group. Clinical risk factors for primary graft dysfunction after lung transplantation. Am J Respir Crit Care Med. 2013;187:527-34.

3. Warneck G, Van Raemdonck D, Smith MA, Massard G, Kukreja J, Rea F, et al. Normothermic ex-vivo preservation with the portable organ care system lung device for bilateral lung transplantation (INSPIRE): a randomised, open-label, noninferiority phase 3 study. Lancet Respir Med. 2018;6:357-67. Erratum in: Lancet Respir Med. 2018;6:e27. 